\title{
Modelling of Photovoltaic systems for real-time hardware simulation
}

\author{
H. Palahalli · Y. Huo · G.Gruosso
}

\begin{abstract}
The Real-time simulation is a valid help to test electrical systems when a physical device is not available. This is significantly evident when used in Hardware and Software co-simulation environment, where it is possible to connect the emulator to a real subsystem to test or validate it. In this paper, a model of the photovoltaic system is presented, that can be implemented within a hardware simulator to be able to interface it with a real circuit, the hardware simulator used is the National Instruments RIO system.
\end{abstract}

\section{Introduction}

Real-time simulation (RT) is one of the frontiers of electrical system analysis. Its task is to control or react to events that occur in the real world, with the same speed as the real world clock. With the aim of having systems that can be interfaced with other software or real systems in order to simulate increasingly complex systems and on a large scale, also taking communication infrastructure into account, as in the case of smart grids [1-4].

It is necessary to be aware of execution time of the simulation system to ensure that it is shorter or equivalent to the selected time step especially in simulating scenarios that cannot normally be performed, for example, to model the high switching characteristics of the converters, a fast processor is required to reach the minimum step size of up to microseconds $[5,6]$. To simulate very quick phenomena in the order of microseconds, it is necessary to think of architectures with more than one processor, and based on FPGAs, that allow high sampling rates, a faster and parallel

H. Palahalli · Y. Huo · G.Gruosso

Politecnico di Milano - DEIB

Piazza Leonardo da Vinci, 3220133 Milano, Italy

e-mail: harshavardhan.palahalli@mail.polimi.it,Yujia.Huo@polimi.it, giambattista.gruosso@polimi.it computing capacity [7]. As the penetration of PV generation increases, its impact on stability and security of the power system will become more and more significant, due to the characteristic of randomness and volatility [8]. Modeling and simulation are the basic technologies to study the impact on the power grid in which, large-scale PV generation systems are integrated. Simulations in the usual platform may give good results, but they are not able to deliver results for dynamic change in input as present in real-world in run-time, the model may not respond for such a change. When we try to simulate to know the long term performance of a system, the normal simulation requires a very long time to deliver results and the accuracy of the results may also get compromised. While simulating the complex model like PV system interaction with the grid in real-time, we may encounter many problems. The important ones to mention are,

1. The need for a PV mathematical model that can deliver results faster to keep the real-time simulation properties during execution. Solving the algebraic loop in the PV model is an important task, as algebraic loops are not supported in the real-time hardware.

2. There is a need of cost-effective test bench/platform for simulating PV systems in real-time that can be used for control validation, studies of the storage system and integration of PV system to the power drive train or grid.

3. Model-based design of process and systems are very popular, there are tools available, for automatic code generation for the developed model, it's required to use these tools, that can deliver $\mathrm{C}$ code from the model, which can be used for the cost-effective target hardware.

4. The memory of the real-time digital Simulator (RTDS) is the main constraint while simulating a complex model, like the grid, this memory is used for storing and executing the compiled $\mathrm{C}$ code in real-time. It may be neces- 


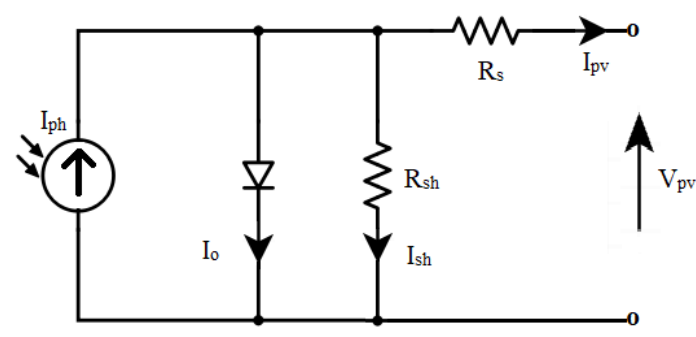

Fig. 1 PV cell equivalent circuit

sary to split the model into two or more separate systems and bridge them using an appropriate interface.

5. Interfacing the two models using respective interfacing algorithm introduces some errors in the execution, that results in, instability of the system during run time and also the accuracy of the results varies according to the interfacing algorithm used.

The main objective of this work is to conduct the real-time simulation of the PV considering as hardware under test (HUT), with the MPPT (Maximum Power Tracking Point) system, storage and the load connected to DC bus acting as a rest of the system (ROS) of hardware-in-the-loop (HIL) simulation methodology. The idea is that the photovoltaic system and the rest of the system are executed in parallel in real time and the maximum power is monitored for irradiation variation in the real world and the extracted power is supplied to the DC bus to which storage element and the fixed load resistance are connected. The modeling of these systems are done in Simulink [9]. The modeled systems are compiled and deployed in NI myRIO's FPGA [10] for realtime simulation.

The rest of this article is organized as follows: Sec. 2 deals with the modeling of photovoltaic and MPPT systems, Sec. 3 explains the real-time simulation architecture used in this work, Sec. 4 tells the real-time simulation with the results and conclusions are drawn in Sec. 5 .

\section{PV system modelling}

The mathematical model of the PV system is drawn accordingly with [11] [12]. The equivalent described in Fig. 1 consists of a current source in parallel with the diode and $R_{s h}$ and $R_{s}$ are the intrinsic shunt and series resistances of the cell, respectively. The I-V characteristic of the cell is determined by the diode. PV cells are grouped into larger units to form PV modules, these modules are connected in series or parallel to create a PV array to obtain required electrical power.

$I_{p h}=\left[I_{s c}+K_{i}\left(T_{c e l l}-T_{r e f}\right)\right] \lambda$

$$
\begin{aligned}
I_{r s} & =\frac{I_{s c}}{\left[\exp \left(\frac{q V_{o c}}{N_{\text {cell }} K n T_{\text {cell }}}\right)-1\right]} \\
I_{o} & =I_{r s}\left[\frac{T_{\text {cell }}}{T_{\text {ref }}}\right]^{3} \exp \left\{\frac{q E_{g}}{n K}\left(\frac{1}{T_{\text {ref }}}-\frac{1}{T_{\text {cell }}}\right)\right\}
\end{aligned}
$$

$$
V_{t}=\frac{K T_{\text {cell }}}{q}
$$

$I_{s h}=\frac{V_{p v} \frac{N_{p}}{N_{c e l l} N_{s}}+I_{p v} R_{s}}{R_{s h}}$

$I_{p v}=N_{p} I_{p h}-N_{p} I_{o}\left[\exp \left(\frac{\frac{V_{p v}}{N_{c e l l} N_{s}}+\frac{I_{p v} R_{s}}{N_{p}}}{n V_{t}}\right)-1\right]-I_{s h}$

Where,

$\begin{array}{ll}I_{p v} & \text { Cell current } \\ V_{p v} & \text { Array terminal voltage } \\ I_{p h} & \text { Photo current } \\ I_{s c} & \text { Short-circuit current at } 25^{0} \mathrm{C} \text { and } 1 \mathrm{~kW} / \mathrm{m}^{2} \\ K_{i} & \text { Short-circuit current temperature coefficient } \\ T_{c e l l}, T_{r e f} & \text { PV Cell and reference temperature in } \mathrm{K} \\ \lambda & \text { Ratio of solar irradiation to reference } 1 \mathrm{~kW} / \mathrm{m}^{2} \\ I_{r s} & \text { Module reverse saturation current } \\ q & \text { Charge on electron }=1.6 \times 10^{-19} \mathrm{C} \\ N_{c e l l} & \text { Number series cells in a module } \\ n & \text { Diode ideal factor } \\ k & \text { Boltzmanns constant }=1.3805 \times 10^{-23} \mathrm{~J} / \mathrm{K} \\ I_{o} & \text { Module saturation current } \\ E_{g} & \text { Energy band gap of semiconductor material } \\ V_{t} & \text { Diode thermal voltage } \\ I_{s h} & \text { Shunt current } \\ N_{s} & \text { Number of series modules connected in string } \\ N_{p} & \text { Number of parallel string connected in array } \\ V_{o c} & \text { Open circuit voltage } \\ R_{s}, R_{s h} & \text { Series and Shunt resistance }\end{array}$

The method to find the resistances of PV cell can be found in [14], the above mentioned Equation 6 is solved using Newton Raphson method with the error tolerance of $10^{-5}$ for better accuracy. In this work Mitsubishi Electric PV-UD180MF5 PV module is selected as reference, the parameters of the module are given in the table 1. The IV curve of the modeled PV array for different irradiation is given in the Figure 2, later the same model is used for PV real-time simulation, fixed step discrete solver with the sample time of $1 \mathrm{~ms}$ is used in both normal and real-time simulation.

The PV panels are connected to the load using an DC/DC converter governed by an MPPT controller, based on perturb 


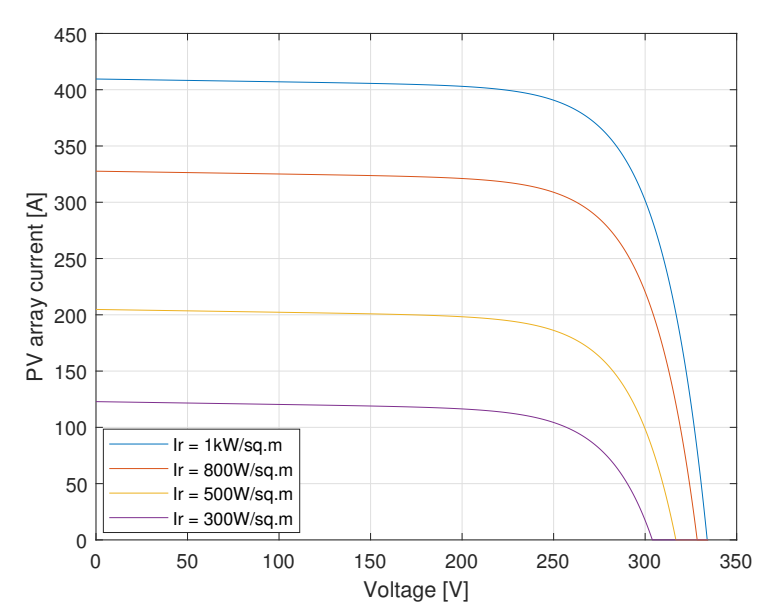

Fig. 2 IV curve of the $100 \mathrm{~kW}$ array for different Irradiation

Table 1 Mitsubishi Electric PV-UD180MF5 PV Module details and parameters for $100 \mathrm{~kW}$ array

$\begin{array}{ll}\text { Parameter } & \text { Value } \\ \text { Open circuit voltage }\left(V_{o c}\right) & 30.4 \mathrm{~V} \\ \text { Short circuit current }\left(I_{s c}\right) & 8.03 \mathrm{~A} \\ \text { Maximum power rating }(\text { Pmax }) & 180 \mathrm{~W} \\ \text { Voltage @ maximum power } & 24.2 \mathrm{~V} \\ \text { Current @ maximum power } & 7.45 \mathrm{~A} \\ \text { Number of series connected cells in module }\left(N_{c e l l}\right) & 50 \\ \text { Diode ideal factor }(\mathrm{n}) & 1.7 \\ \text { Band Energy Gap }\left(E_{g}\right) & 1.121 \mathrm{eV} \\ I_{s c} \text { temperature Co-efficient } k_{i} & 0.0032 K^{-1} \\ \text { Shunt resistance }\left(R_{s h}\right) & 3.767 \Omega \\ \text { Series resistance }\left(R_{s}\right) & 0.00019 \Omega \\ \text { Number of series modules used } N_{s} & 11 \\ \text { Number of Parallel Strings used } N_{p} & 51\end{array}$

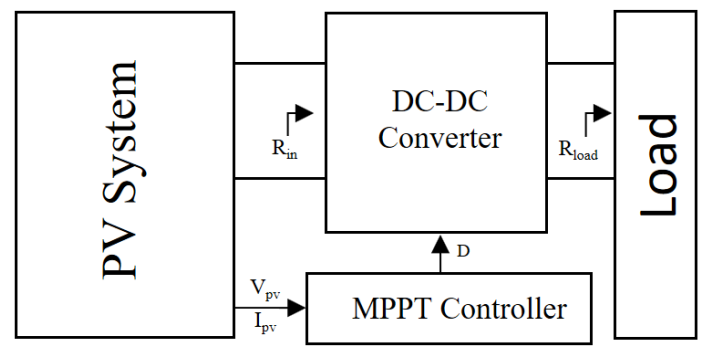

Fig. 3 Block diagram of PV system with MPPT

and observe $(P \& O)$ method. The choice of a DC-DC converter is based on many factors such as load resistance, resistance at the maximum power point, DC output voltage [13]. The Fig. 3 shows the block diagram of PV with MPPT system.

\section{Real-time Simulation Architecture}

In this section the test-benches created for conducting HIL experiment will be presented. The mathematical model will be simulated in myRIO in real-time. FPGA IO's are used to

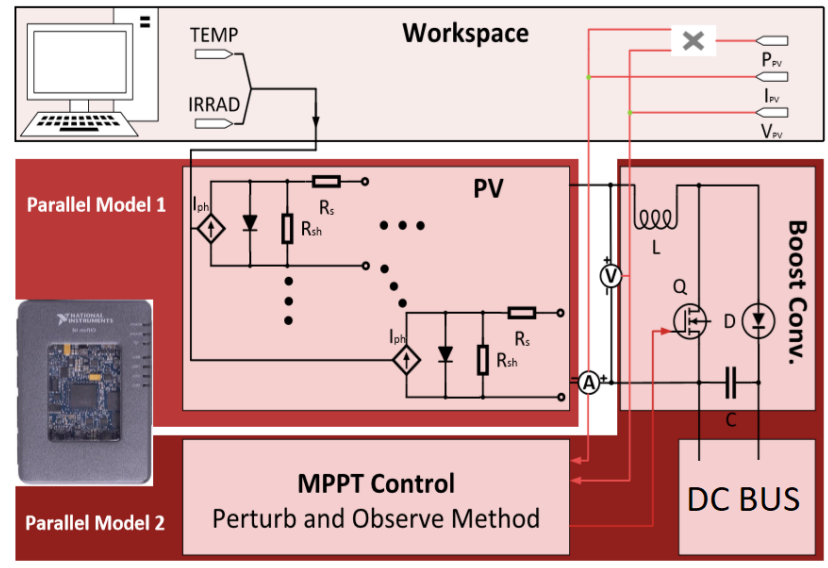

Fig. 4 PV with MPPT system in myRIO

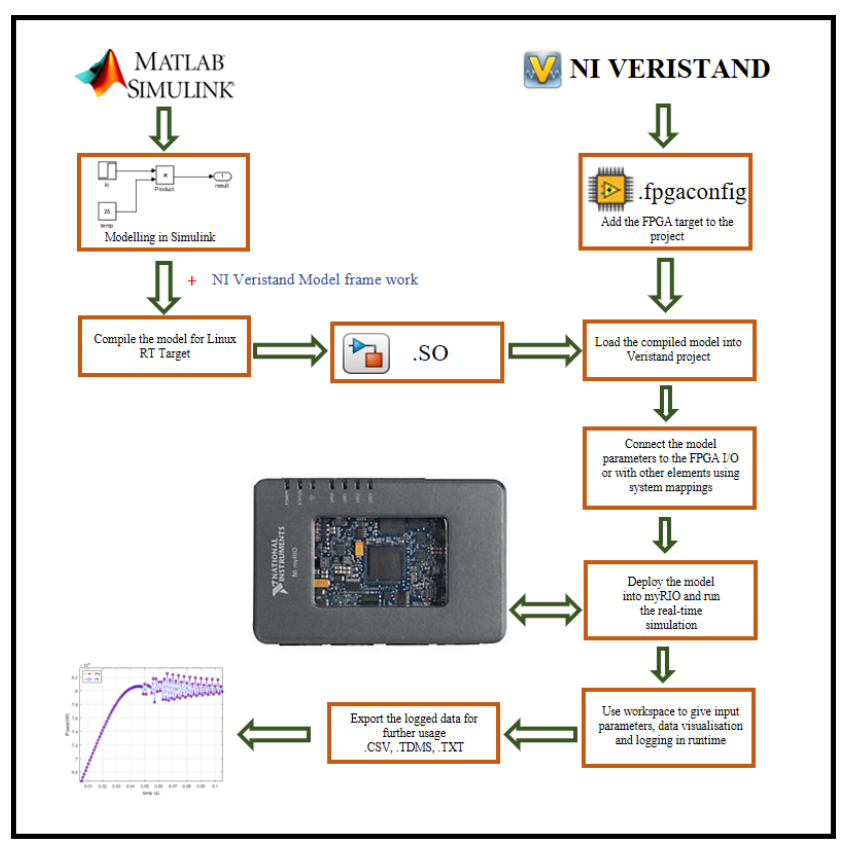

Fig. 5 Functional Scheme of the procedure

integrate the model in-ports and out-ports to the real world measurement systems.

The model will be implemented in MATLAB-Simulink [9] and translated in into $\mathrm{C}$ code with its internal $\mathrm{C}$ code generating tool using the NI VeriStand compilers which adds on to the MATLAB and it can generate the file ".SO" which defines our model with the libraries. NI VeriStand Engine has to be deployed in the RT target to make it compatible to run with the host computer. lvbitx file defines the custom FPGA personality used for simulation in the RT target. The main operation are shown in the fig. 5. National Instruments myRIO-1900 is a Linux based device, it comes with built-in Xilinx Z-7010 FPGA[10] and it also allows us to build custom FPGA applications with real-time capabilities. In this study, the real-time simulation of PV system is 
done in myRIO using NI Veristand [10], it is a configurationbased testing software, specifically designed to run the realtime testing application, thus allowing us to develop and test control system using hardware I/O and simulation models.

\section{Simulation and Results}

This test-bench consists of a $100 \mathrm{~kW}$ PV array model as HUT, whose interaction with the ROS for the change in temperature and the irradiation is studied. The ROS consists of MPPT, DC-DC converter, DC bus is created where the load and the storage are connected with the breaker and the bidirectional intelligent converter respectively. The temperature and the irradiation data are measured using a temperature sensor and a small 5W PV cell respectively. The model used to simulate using this test-bench is shown in the Fig. 6.

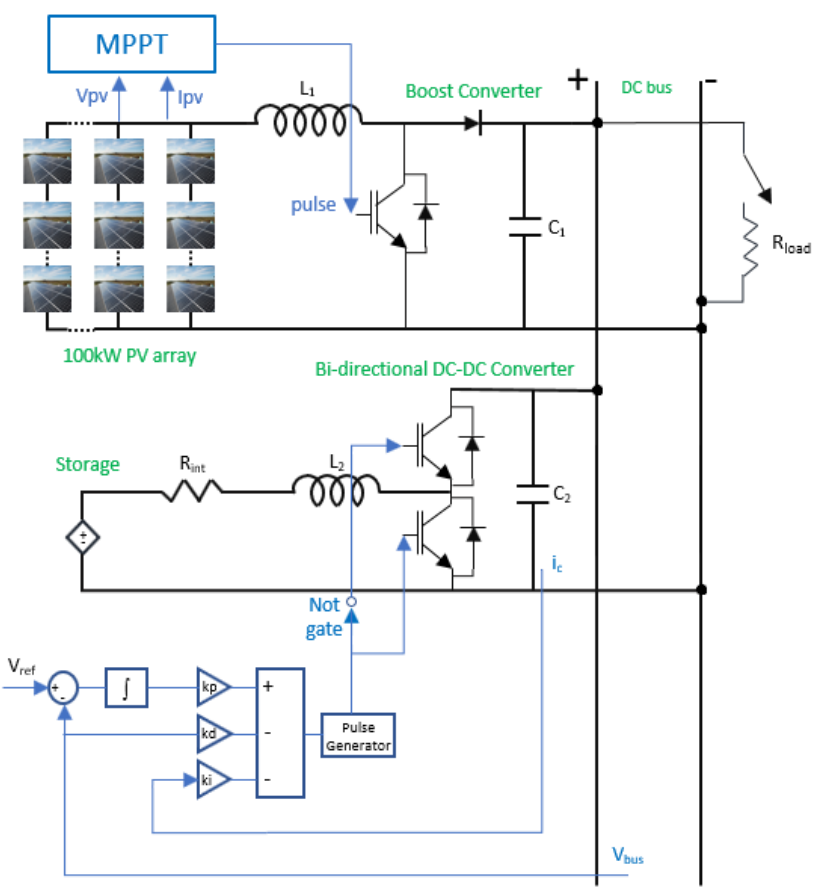

Fig. 6 Block diagram of the simulated model

The power rating and other parameters of the proposed RT simulated system are given in the table 2 , the voltage of DC bus is maintained at $250 \mathrm{~V}$ all the time with the help of storage and the bi-directional DC-DC converter, which allows the power flow in both the directions. PID control is used for the voltage control of the converter. When the power required by the load, is more than the generation, DC bus voltage drops. Power will be compensated by the energy stored and the voltage is brought regulated. When the power generated is more than the load requirement, the DC bus voltage increases, and the controller takes action to bring
Table 2 Parameters of Electric system

$\begin{array}{ll}\text { Parameter } & \text { Value } \\ L_{1} & 11 \mathrm{mH} \\ C_{1} & 10 \mathrm{mF} \\ \text { MPPT switching frequency }\left(f_{s 1}\right) & 1 \mathrm{kHz} \\ R_{\text {int }} & 0.14 \Omega \\ L_{2} & 15 \mathrm{mH} \\ C_{2} & 10 \mathrm{mF} \\ \text { Controller gains, kp } & 0.055 \\ \mathrm{ki} & 0.001 \\ \mathrm{kd} & 0.0003 \\ \text { Bi-directional converter }\left(f_{s 2}\right) & 5 \mathrm{kHz} \\ \text { Nominal Voltage of battery } & 140 \mathrm{~V} \\ \text { Initial SOC of battery } & 50 \% \\ \text { DC Bus voltage } V_{\text {bus }} & 250 \mathrm{~V} \\ R_{\text {load }} & 1 \Omega \\ \text { Sample time used in RT simulation } & 1 \mathrm{~ms}\end{array}$

back the voltage to the set reference of $250 \mathrm{~V}$. In this experiment, the fixed resistive load of $1 \Omega$ is connected to the DC bus at $5^{\text {th }}$ second, The outputs are driven to the real world using FPGA IO and read using the digital oscilloscope, the test bench setup is shown in the Fig. 7.

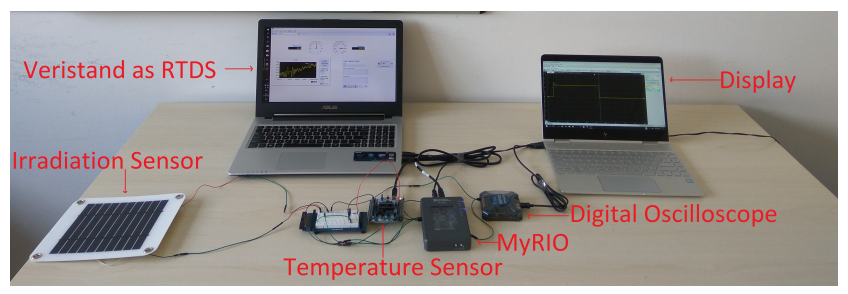

Fig. 7 Test-bench used for HIL simulation

The irradiation and the temperature measured in realtime is given in the Fig. 8. They both are measured by myRIO and fed to the model during run-time.
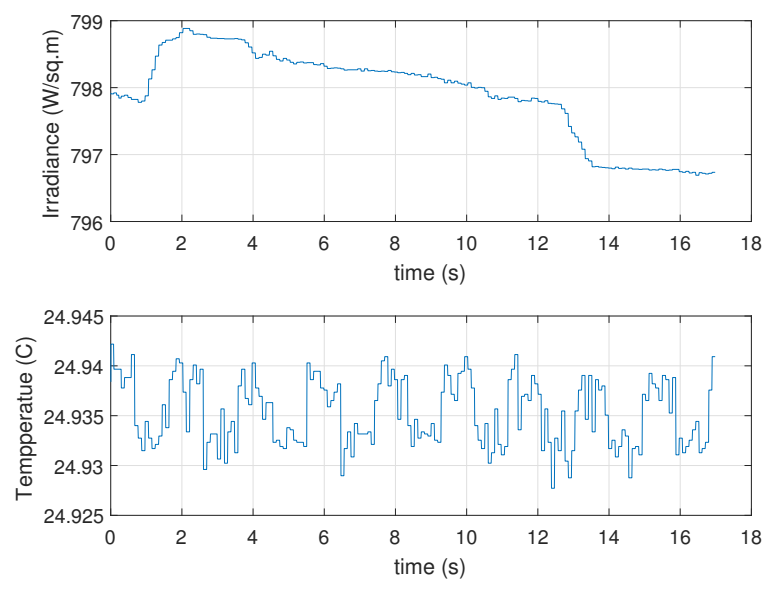

Fig. 8 Irradiation and temperature measured in real-time 
The load is connected to the DC bus at $5^{\text {th }}$ second, the DC bus voltage and it's variations during run-time is given in the Fig. 9. It can be observed that the controller is able to maintain the bus voltage constant even after connecting load at $5^{\text {th }}$ second.

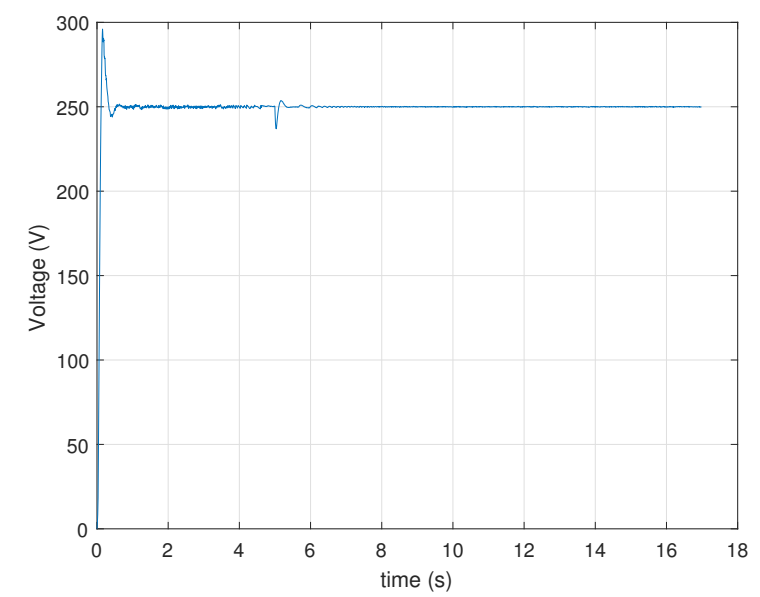

Fig. 9 Voltage measured across DC bus in real-time

To ensure the simulation running in real-time the bus voltage is also measured using a digital oscilloscope as shown in Fig. 10. The real-time simulation started at $-9 \mathrm{~s}$, this corresponds to $0^{t h} \mathrm{~S}$ of the model time, the load is configured to get connected to the DC bus at $5^{\text {th }} \mathrm{s}$ of the model time, and in the oscilloscope the voltage variation due to load application is recorded at $-4^{\text {th }} \mathrm{s}$, this proves that the simulation is running in real-time, just the voltage is scaled down by $100 \mathrm{~V}$ as $1 \mathrm{~V}$ to drive output through DAC, finally the simulation is stopped at $1.6 \mathrm{~s}$ as seen in oscilloscope.

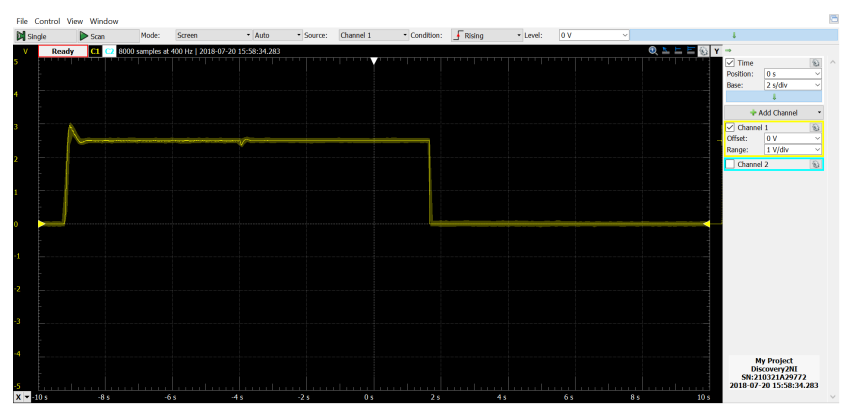

Fig. 10 Voltage measured across DC bus using oscilloscope

The maximum power delivered by PV and the power consumed by the load after connecting it to the DC bus is shown in the Fig. 11. The power delivered by PV before connecting the load, is used to charge the storage system of 10Ah. The state of charge measured in the storage system and the current flowing to the batteries are given in the Fig.
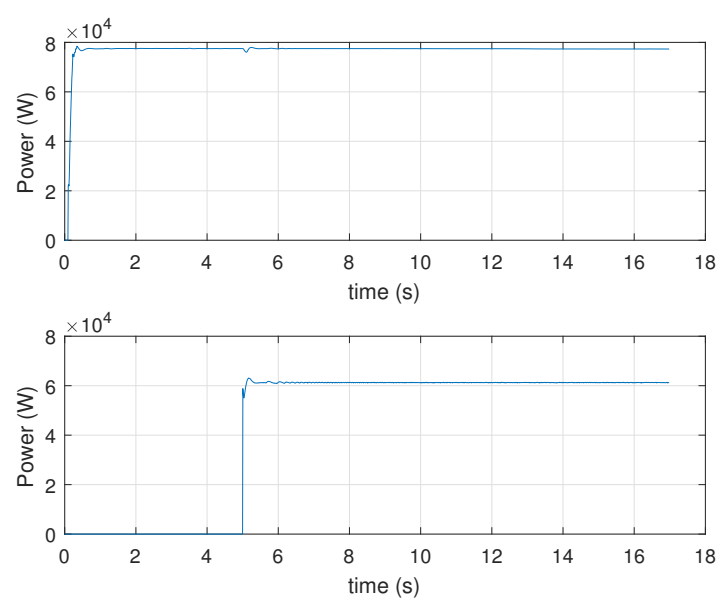

Fig. 11 Power delivered by PV and consumed by load

12. Initial SOC is about $50 \%$ and raised rapidly till connecting the load to the DC bus, later the slope of SOC decreases since the flow of current is decreased to the storage system. The voltage seen across the storage system throughout the simulation is given in the Fig. 13.
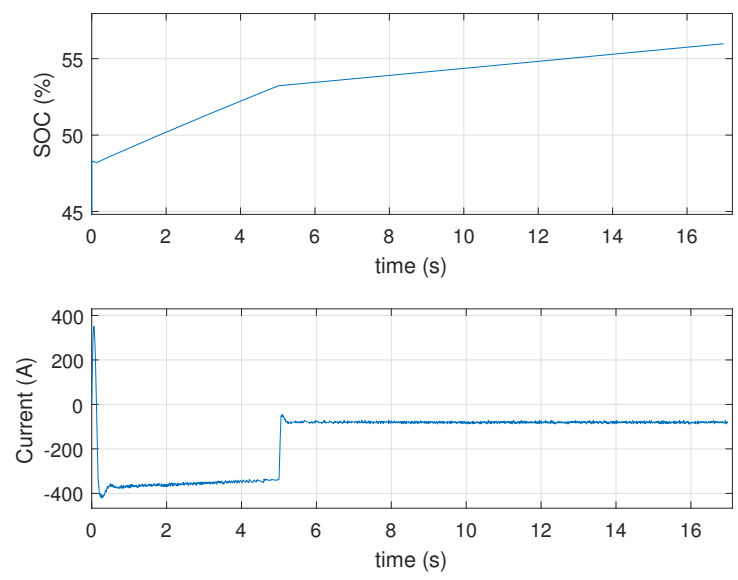

Fig. 12 SOC and the battery current

\section{Conclusion}

This article presents a methodology for real-time simulation, based on a model created in Simulink environment and then downloaded to the hardware of National Instruments. The step is done through Veristand tool, to demonstrate that, it is possible to create small real-time simulators for laboratory or educational use. In the article, the methodology is illustrated in detail and accompanied by the results. 


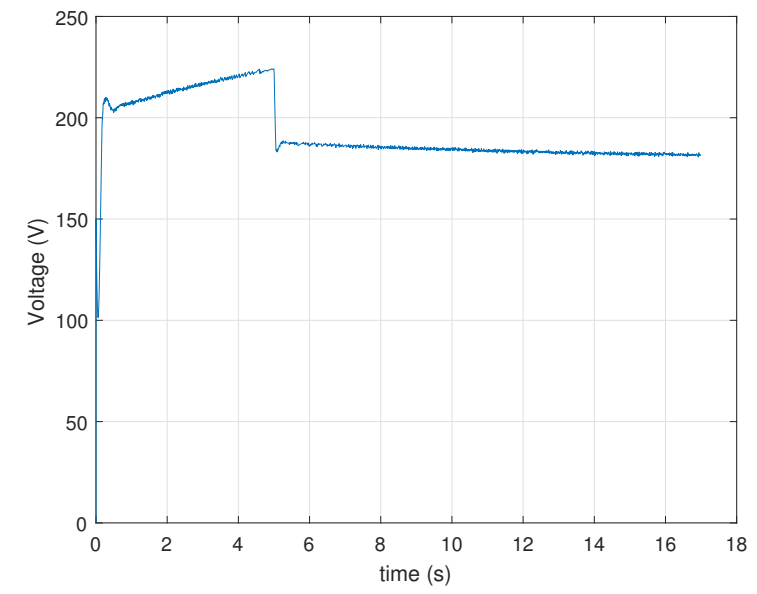

Fig. 13 Battery terminal voltage

\section{References}

1. Y. Huo, G. Gruosso, and L. Piegari. Power hardware in the loop simulator of photovoltaic plant for smart grid interation analysis. In 2017 IEEE International Conference on Environment and Electrical Engineering and 2017 IEEE Industrial and Commercial Power Systems Europe (EEEIC / I CPS Europe), pages 1-5, June 2017.

2. MD Omar Faruque, Thomas Strasser, Georg Lauss, Vahid JaliliMarandi, Paul Forsyth, Christian Dufour, Venkata Dinavahi, Antonello Monti, Panos Kotsampopoulos, Juan A Martinez, et al. Real-time simulation technologies for power systems design, testing, and analysis. IEEE Power and Energy Technology Systems Journal, 2(2):63-73, 2015.

3. Aravind Ingalalli, Hariram Satheesh, and Mallikarjun Kande. Platform for hardware in loop simulation. In Power Electronics, Electrical Drives, Automation and Motion (SPEEDAM), 2016 International Symposium on, pages 41-46. IEEE, 2016.

4. Wei Li, Géza Joós, and Jean Bélanger. Real-time simulation of a wind turbine generator coupled with a battery supercapacitor energy storage system. IEEE Transactions on Industrial Electronics, 57(4):1137-1145,2010

5. PM Menghal and A Jaya Laxmi. Real time control of electrical machine drives: A review. In Power, Control and Embedded Systems (ICPCES), 2010 International Conference on, pages 1-6. IEEE, 2010.

6. Benjamin L Schenkman, David G Wilson, and Rush D Robinett. Photovoltaic distributed generation for lanai power grid real-time simulation and control integration scenario. In Power Electronics Electrical Drives Automation and Motion (SPEEDAM), 2010 International Symposium on, pages 154-157. IEEE, 2010.

7. M Dagbagi, L Idkhajine, E Monmasson, and I Slama-Belkhodja. Fpga implementation of power electronic converter real-time model. In Power Electronics, Electrical Drives, Automation and Motion (SPEEDAM), 2012 International Symposium on, pages 658-663. IEEE, 2012.

8. J V ,Paatero, P. D., Lund Effects of large-scale photovoltaic power integration on electricity distribution networks Renewable Energy,32(2):216-234,2007,Elsevier

9. The Mathworks, http://www.mathworks.com/

10. National Instruments, http://www.ni.com

11. F. Bizzarri, A. Brambilla, G. Gruosso, C. Guardiani, A. Sangiovanni Vincentelli, and G. Storti Gajani. Modeling and estimating yield and efficiency of photovoltaic solar parks. In 2013 IEEE International Conference on Industrial Technology (ICIT), pages 734-739, Feb 2013.
12. F. Bizzarri, M. Bongiorno, A. Brambilla, G. Gruosso, and G. S Gajani. Model of photovoltaic power plants for performance analysis and production forecast. IEEE Transactions on Sustainable Energy, 4(2):278-285, April 2013.

13. M. Pisano, F. Bizzarri, A. Brambilla, G. Gruosso, and G. S. Gajani. Micro-inverter for solar power generation. In International Symposium on Power Electronics Power Electronics, Electrical Drives, Automation and Motion, pages 109-113, June 2012.

14. Sumathi, S and Kumar, L Ashok and Surekha. Application of MATLAB/SIMULINK in solar PV systems. Solar PV and Wind Energy Conversion Systems, pages 59-143, year 2015, publisher Springer. 